\title{
What 'Professionalism' means to me! an academic reflects!
}

\author{
Meenakshi Akhilesh
}

\begin{abstract}
As the years pass by and my students walk the corridors of the universities and later the hospitals, an incident got me thinking about a subject that we as academics teach and often hope that our students imbibe to the best of their ability. After all, we muse at times, it is getting more difficult to 'teach' professionalism in ever evolving curricula and ever changing societies. 'Professionalism' I am aware has become fashionable in its use among nonacademics such as those in the industry also. So, I decided to define professionalism once again as I had done many times in the past as a medical student, as a medical officer, as a registrar and later as a teacher. Every time I found that the meaning of the word 'professionalism' had grown and evolved as I had in my journey down the corridors of the medical school.
\end{abstract}

Professionalism to me then was 'a list', but now it is personal, is impacted by personality and is always going to be priority. We all began our lessons in professionalism with alma maters that have long stood the test of time, their sanctums and their imagery revered and sanctified through years of belief in their value systems that are being handed down year after year. But we must all recognize the importance of calibrating our thoughts and actions from time to time as we strive to achieve the right balance every time.

To me professionalism translates as 'responsibility' to work in a well-designed, clean, work oriented and disciplined culture which academics must embrace with immense dignity and pride. Precision, productivity and pride towards my responsibilities feature

Clinical Associate Professor

Newcastle University Medicine Malaysia

No. 1, Jalan Sarjana 1,

Kota IImu,

EduCity@Iskandar,79200 Nusajaya,

Johor, Malaysia strongly in my life as a teacher. We as academics wear mantles that reflect our roles as models for our students as we make concerted efforts to leave indelible marks on their impressionable minds. Our efforts will translate in the years to come in the way our students behave, hopefully displaying dignity and professionalism in all their interactions.

Professionalism for me translates as 'respect' towards my patients, my students, their parents, their guardians, my seniors, my peers and colleagues, my teachers and the institution that I represent in all manner of thought, word and deed. It is also excellence that translates as 'taking the road less trodden' or taking the 'risk' to improvise and innovate to make learning an experience that nurtures, challenges and guides students in their quest for learning.

Professionalism to me is not a guide or a 'todo list' anymore. It is personal! It is my legacy to my students. It is a tapestry of experiences that have shaped my thoughts and interactions. It has to do with the people that moulded me to integrate and innovate towards influencing positive societal changes. It is not about personalities but attitudes. It is about standing up for what matters now and what will continue to matter in a dynamic world.

To quote Patricia Phelps, Professionalism refers to "the internalized beliefs ... regarding professional obligations, attributes, interactions, attitudes, values, and role behaviours."... Three primary indicators constitute the meaning of professionalism: responsibility, respect, and risk taking.

So, as I continue redefining my original definition of 'Professionalism' I smile to myself because a lot has changed and yet a lot remains as it was all those years ago. 